\title{
Belief System \& Mind Patterns: Conceptual Overview of Impact on Women's Reproductive Health
}

\author{
Ms. K. Ramya \\ Doctoral Research Scholar \\ Department of Women's Studies \\ $\&$ \\ Dr. K. Manimozhi \\ Professor \\ Department of Resource Management \\ \& \\ Controller of Examinations (i/c) \\ Avinashilingam Institute for Home Science \& Higher Education for Women \\ (Deemed University) \\ Coimbatore, Tamil Nadu, India
}

\begin{abstract}
A woman's reproductive system is one of the delicate and complex parts of the body and there are numerous factors that affect it causing dysfunction of the associated organs. Various biological and psychological changes occur in the body that are connected to the reproductive system. Many researches have been carried out about how specific medical conditions, genetic factors, hormonal fluctuations, stressful life events, psychological factors, socioeconomic \& cultural factors, changes in lifestyle, etc. act as contributors to women's reproductive health. This research focuses on how one's belief system, thought process and mind patterns induces complications or pathological conditions within the reproductive system as well as overall well-being of women. Suggestions are given on how women can change their limiting beliefs, thereby embracing womanhood to lead a healthy life.
\end{abstract}

Keywords: Reproductive Health, Belief System, Mind Patterns, Women's Mental Health.

\section{Introduction}

A woman's reproductive health refers to the condition of female reproductive system during all stages of life, in which the system is made of multiple organs and hormone-producing glands. The World Health Organization defines reproductive health as a state of complete physical, mental and social well-being and not merely the absence of disease or infirmity in all matters relating to the reproductive system 
and to its functions and processes. An individual's overall health including the functioning of all body organs as well as mental capacity begins at the time of conception. Various factors contribute to a person's physical and mental health right from the foetal stage to a full grown adult, which includes hereditary influences, family environment, economic status of the family, nutritional state, cultural impacts and rituals, knowledge gathered from own experiences, etc.

In today's fast-paced world, women are facing numerous disorders and complications pertaining to their reproductive system. A few common disorders include early or delayed puberty, menstrual problems including heavy or irregular bleeding, polycystic ovarian syndrome, endometriosis, fibroids and tumors, infertility or reduced fertility, etc. Some of the known facts and ways to maintain a healthy reproductive system for women include eating a balanced diet and drinking plenty of water, exercising regularly and maintaining weight, getting enough sleep, managing stress in healthy ways, etc. Though numerous physical, environmental and lifestyle factors contribute to these disorders, research can be focused on mind patterns and belief system one has developed pertaining to oneself, the role one plays, womanhood, femininity and what are the limiting beliefs that are likely to have a negative impact on the reproductive system.

\section{Beliefs \& Formation of Belief System}

Beliefs are important foundation of one's attitude and behavior. It is the mental acceptance or conviction in truth or actuality of an idea. The core beliefs that govern our behavior and reality are stored both in the conscious and unconscious part of our mind and these have impact on our actions, decisions, goals, thought patterns and feelings. The purpose of belief is to provide meaning to thoughts and ideas we hold about ourselves, making sense of where we are and the role we play in this world. According to Lazarus and Folkman (1984), our attitudes, behaviours and ability to cope can be attributed to direct or indirect beliefs we hold. An individual's beliefs are created through mental processes which involves perception, attention, valuation, storage and updating information (Seitz, Paloutzian \& Angel, 2017). Thus, beliefs form the basis for interacting with the world and are also involved in coordinating cognitive processes, social processes, foundation for identity, social cohesion and social conflict. In addition to this, beliefs are vital in understanding various psychiatric and psychological pathologies. Hence, beliefs provide a better understanding of cognitive systems, social dynamics and ourselves (Connors \& Halligan, 2015).

\section{Contributors to Belief System}

Belief systems are often formed during our childhood from our families, environment and from our own experiences and perspectives, and these are the foundation for our mental health. Any thought patterns that we exhibit consistently 
becomes a belief and the beliefs we perpetuate over time becomes our belief system. Our belief system has an impact on how we think and feel and also how we behave and operate our lives.

When a belief is formed with strong emotions, it can remain unchanged in the subconscious until we take effort to change it consciously. It is these beliefs which are formed during childhood remain unchanged and cause problems even as adults. The limiting beliefs we have about ourselves affects our mental health.

Some common limiting beliefs are as follows:

a) Life is a struggle

b) My family doesn't understand me

c) Nobody loves me

d) I never succeed

e) I have to be in control all the time

f) I can't trust anyone

g) No one can help me

h) I don't do things perfectly

i) I am not good enough

j) Whatever I do, no one appreciates me

k) There is no use in complaining, it's pointless

The above-mentioned beliefs are formed over years based on life sequences and one's own experience. The sequences which have occurred in the past continues in the present as the mind is convinced these are true and cannot be changed. However, if one takes an initiative to observe what has caused all the similar patterns and what can be done to change this, then the process becomes easier and changes begin to happen. For e.g. if a child scores average marks continuously for a period of time and is put down by his/her family that this is the level of the child and will not improve, the child starts believing the same and diminishes his/her ability to improve or progress further. The mind of the child says, "whatever I do, they will say the same thing, they will not appreciate, so let me be the same". However, if the child decides at that point or even as an adult that, "whatever has happened is in the past, but now I can prove to my family as well as myself that I can do better in my studies/in my life and I am not that same average person anymore", then this new thought becomes a new belief and the child/adult starts working towards it.

\section{Womanhood \& Limiting Mind Patterns}

Womanhood refers to the state or qualities that are considered to be natural characteristics of a woman. Generally, the qualities of womanhood or femininity include gentleness, humility, sensitivity, etc. This chapter focuses mainly on Indian 
women and how they perceive womanhood, what kind of belief system they have developed about themselves and life in general as well as thought process and mind patterns related to being a woman, etc. The moment a baby is born, the first question is, "Is it a boy or girl?", and this refers to more than just a biological question. Even though our culture talks about divine feminine energies and qualities such as creativity, receptivity, healing, motherhood, nurturing, love, compassion, forgiveness, sensuality, etc., the social norms are constructed in such a way that woman is considered as extra responsibility or a burden to the family. A girl child is exposed to a specific set of rules and restrictions, social regulations and appropriate feminine behaviour right from the birth. Not every family has same rules and even families belonging to the same religion or caste do not practice or impose same set of cultural patterns on their girl child. However, there are a few common belief patterns, which includes "family's needs comes first, you have to be patient all the time, you cannot express your anger, you have to be dependent on men, father's or husband's decision is final, etc."

One creates a perception about womanhood and beliefs about the role of females from the family and society, which is constantly fed into the mind as negative thought patterns. The impact of these beliefs and patterns along with other contributing factors such as gender discrimination, lack of appreciation, constant criticism and so on is likely to affect a woman's mental health and in turn her reproductive system.

The thoughts and beliefs along with underlying emotions that one has developed over years contributes to overall health. A few examples of thought processes and beliefs are:

- My mother always criticizes me, my father always supports me

- I can rely on my siblings for support and care

- My opinion doesn't matter

- I can't trust my friends

- My hard work is never recognized

- My husband understands me

- My husband doesn't listen to me

- I can share anything with my friend

- No one gets my point

- My sister always looks up to me

- I am not their favourite child

- People treat me like this because I am a woman

Each and every thought process, either positive or negative, contributes to one's perception about self and life, frames one's attitude and behaviour and develops one's ability to handle life's sequences. 


\section{Probable Mental Patterns \& Impact on Reproductive Health}

The hormones that regulate the female reproductive system are nurtured by one's thoughts, emotions and beliefs. When the thoughts and mind patterns are persistently bothering oneself being a woman, all things pertaining to feminine process becomes a burden. According to Hay (1984), belief system about being a woman, self-criticism, feelings of disempowerment, disrespected, confusion, anxious, anger, self-doubt, lack of self-love and not trusting the natural flow of life acts as major contributors to menstrual disorders and rejection of the feminine process.

Our bodies respond to our inner thoughts, beliefs and emotions and other possible external factors. A possible cause for menstrual disorders may be difficulty in accepting one's femininity. For instance, one might have had a negative/unpleasant relationship with their mother, mother's or family's expectations imposed on the girl child, one's perception about women and their roles in the society, being discriminated against a male sibling, belief that men have more opportunities than women, beliefs and customs about menstruation and associated rituals, etc. These set of life sequences might give consistent thoughts and feelings that it would be better if one had been born as a man.

\section{Changing Roles in Current Scenario}

Women nowadays are taking active roles both in the family and society unlike the earlier generations. Growing financial needs, being independent and self-sufficient, creating one's identity and earning recognition, constant need to prove oneself in the family and professionally, socio-economic contribution as well as coping up with various life's demands have become a challenge especially if there is lack of emotional or moral support in the family. Apart from the external stressors including work stress, one's motivation level plunges due to misunderstanding and interpersonal conflicts within the family. This results in lack of self-care, thereby deteriorating one's physical and mental health.

\section{Belief Change \& Embracing Womanhood}

The first step towards any change would be asking oneself, "Am I going to be in this same position? What can I do to change my situation?" Though the process of change is difficult and tedious, one has to decide to begin at some point. Being open to making changes will help us find ways to do them. One can seek professional help in facilitating the process of change and the belief systems. Hay gives a set of affirmations/positive statements to come out of limiting patterns and create new ones (Hay, 1984; Hay 2007). 
- Female / Menstrual Problems - Denial of the self. Affirmation- "I rejoice in my femaleness. I love being a woman. I love my body."

- Ovaries represents point of creativity and issues with the ovaries may be due to one's inability to express or accept own areas of creativity. Ovarian cysts may represent regrets, holding onto old hurts, low self-esteem, fear of being hurt, feelings of neglect, unloved or not feeling good enough, etc.

Affirmation- "I am balanced in my creative flow. I choose to make my life beautiful. I love me".

- Endometriosis could indicate that one is allowing old limiting beliefs to prevent from creating what one want in life. One may feel disappointed, frustrated, unsupported, unloved, holding onto feelings of rejection, thereby rejecting the feminine aspect.

Affirmation - "I am both powerful and desirable. It's wonderful to be a woman. I love myself and I am fulfilled."

- Amenorrhea indicates that one might find it difficult or uncomfortable to be a woman. One may carry resentment towards their mother, feel like a weak and fragile daughter not wanting to take care of oneself, very demanding or being hard on self or others, disliking self, over-stressing, etc.

Affirmation - "I rejoice in who I am. I am a beautiful expression of life, flowing perfectly at all times."

- Premenstrual Syndrome (PMS) can indicate denying feminine energy and rejection of the feminine processes, may feel uneasy about womanhood, inferior, disrespected, confused, anxious, angry, self-doubt, lack of self-love and not trusting the natural flow of life.

Affirmation - "I now take charge of my mind and my life. I am a powerful, dynamic woman. Every part of my body functions perfectly. I love me."

Similarly, McHugh (2009) has proposed belief change exercise that can be used to convert limiting beliefs into healthy ones. The mind is conditioned and programmed by numerous factors and it's one's choice to come out of these conditioned frames and reframe them to accommodate many life's choices. Exercises are devised in such a way that unconscious part of the mind takes care of the healing and changing process through visualization techniques so as to create new attitude or perception, transform a negative thought or behaviour into a positive one.

\section{Suggestion}

The future researchers shall conduct a comprehensive study on women's belief system along with behavioural patterns to understand their reproductive health and its associated aspects. 


\section{Conclusion}

Accepting the natural feminine process will enable women to come out of their rigid or limiting thought patterns about their ability and capacity to overcome difficulties and create new life patterns. Developing assertiveness, voicing out one's needs, respecting self and embracing womanhood can help women overcome their existing beliefs about being a woman and take care of their overall health.

\section{References}

Connors, M. H. \& Halligan, P. W. (2015). A Cognitive Account of Belief: A Tentative Road Map, Frontiers in Psychology, Vol.5, No.1588, pp.1-14.

Hay, L. L. (1984). You can Heal Your Life, Hay House Publishing, USA.

Hay, L. L. (2007). Heal Your Body $4{ }^{\text {th }}$ Edn., Hay House Publishers, India.

Lazarus, R. S. \& Folkman, S. (1984). Stress, Appraisal, and Coping, Springer Publishing Company, New York.

McHugh, R. P. (2009). Mind with a Heart: Creative Patterns of Personal Change, Gujarat Sahitya Prakash, Anand, India.

Seitz, R. J., Paloutzian, R. F. \& Angel, H. F. (2017). Processes of Believing: Where Do They Come From? What Are They Good For? F1000Research, Vol.5, No.2573, pp.1-21.

\section{Webliography}

https://f1000research.com/articles/5-2573

http://psychology.iresearchnet.com/social-psychology/attitudes/beliefs/

https://www.psychologytoday.com/us/blog/our-health/201312/belief-and-its-effect-ourhealth

https://thriveglobal.com/stories/how-your-subconscious-beliefs-affect-your-life/ https://thriveglobal.com/stories/how-to-re-program-your-mind-using-affirmations/ https://thriveglobal.com/stories/knowing-thyself-on-the-importance-of-establishing-thebridge-between-conscious-and-subconscious-mind/

https://www.who.int/westernpacific/health-topics/reproductive-health https://www.takingcharge.csh.umn.edu/how-do-thoughts-and-emotions-affect-health 